\title{
Dual Role of Fas/FasL-Mediated Signal in Peripheral Immune Tolerance
}

\author{
Akiko Yamada, Rieko Arakaki, Masako Saito, Yasusei Kudo and Naozumi Ishimaru* \\ Department of Oral Molecular Pathology, Tokushima University Graduate School of Biomedical Sciences, Tokushima, Japan
}

\section{OPEN ACCESS}

Edited by:

Hideo Yagita,

Juntendo University, Japan

Reviewed by:

Christopher E. Rudd,

Université de Montréal, Canada

Jocelyne Demengeot,

Instituto Gulbenkian de Ciência,

Portugal

*Correspondence:

Naozumi Ishimaru

ishimaru.n@tokushima-u.ac.jp

Specialty section:

This article was submitted

to Immunological Tolerance and Regulation,

a section of the journal

Frontiers in Immunology

Received: 01 July 2016

Accepted: 21 March 2017

Published: 05 April 2017

Citation:

Yamada A, Arakaki R, Saito M, Kudo Y and Ishimaru N (2017) Dual Role of Fas/FasL-Mediated Signal in

Peripheral Immune Tolerance.

Front. Immunol. 8:403.

doi: 10.3389/fimmu.2017.00403
Fas-mediated apoptosis contributes to physiological and pathological cellular processes, such as differentiation and survival. In particular, the roles of Fas in immune cells are complex and critical for the maintenance of immune tolerance. The precise pathways and unique functions associated with Fas/FasL-mediated signaling in the immune system are known. The dual character of Fas/FasL-mediated immune regulation that induces beneficial or harmful effects is associated with the onset or development of immune disorders. Studies on mutations in genes encoding Fas and FasL gene of humans and mice contributed to our understanding of the pathogenesis of autoimmune diseases. Here, we review the opposing functions of Fas/FasL-mediated signaling, bilateral effects of Fas/FasL on in immune cells, and complex pathogenesis of autoimmunity mediated by Fas/FasL.

Keywords: Fas, FasL, T cell, B cell, apoptosis, activation-induced cell death, autoimmunity, immune tolerance

\section{INTRODUCTION}

Fas receptor (CD95, tumor necrosis factor receptor superfamily member 6) is a death receptor (DR) localized on the surface of various cells, which triggers a signal transduction pathway leading to apoptosis $(1,2)$. The interaction of Fas with its ligand FasL (FasL/CD95L) regulates numerous physiological and pathological processes that are mediated through programmed cell death (3). The beneficial and harmful effects of Fas-mediated apoptosis on the immune system were identified after the discovery (4-6). Moreover, signaling downstream of Fas is intricately regulated by numerous pathway components (7-9).

MRL-lpr/lpr mice bear mutations in the gene encoding Fas and serve as a widely used model for autoimmune diseases, such as systemic lupus erythematosus (SLE), rheumatoid arthritis (RA), Sjögren's syndrome (SS), and autoimmune lymphoproliferation syndrome (ALPS) (10, 11). Fasmediated apoptosis of peripheral $\mathrm{T}$ cells, which represents a key mechanism that maintains immunological tolerance, is impaired in MRL-lpr/lpr mice. This mechanism, known as activation-induced cell death (AICD), deletes overactivated or autoreactive $\mathrm{T}$ cells in the periphery (12). The deletion of peripheral T cells by AICD is impaired in MRL-lpr/lpr mice, leading to increased autoreactive T cells that trigger the induction of autoimmune lesions in multiple organs $(10,13)$. Moreover, mutations in the gene encoding Fas occur in patients with ALPS $(14,15)$.

By contrast, FasL expression on the cell surface is specific to the immune system. For example, FasL expression by $\mathrm{T}$ cells is associated with their activation (4). FasL is unstable because it is shed

Abbreviations: AICD, activation-induced cell death; ALPS, autoimmune lymphoproliferation syndrome; TNF- $\alpha$, tumor necrosis factor-alpha; TRAIL, TNF-related apoptosis-inducing ligand; TRAF2, TNF receptor-associating factor 2; TCR, T-cell receptor; cFLIP, caspase-8-like inhibitory protein, NF-kB, nuclear factor-kappa $\beta$. 
from the cell surface through the action of certain enzymes $(16,17)$. When soluble FasL (sFasL) binds to Fas, cell proliferation, but not apoptosis, is induced (18). Mice with the gld/gld genotype bear mutations in the gene encoding FasL, and they are widely used as a model of autoimmune disease (19, 20). Moreover, mutations of the gene encoding FasL occur in patients with ALPS $(14,15,21)$, and FasL is expressed by thyroid, endothelial, and corneal cells (22-24). Expression of FasL by cells residing in "immunoprivileged site" protects them from attack by activated or autoreactive lymphocytes (5).

This review describes the multiple functions of Fas/FasL in the immune system with focus on duality of Fas/FasL signaling in immune regulation and autoimmunity.

\section{Fas-MEDIATED APOPTOSIS}

Fas protein has 319 amino acids and the predicted molecular weight is $48 \mathrm{kDa}$. The mature protein is divided into three domains: an extracellular domain, a transmembrane domain, and a cytoplasmic domain. The extracellular domain consists of 157 amino acids with cysteine-rich domain. The transmembrane and cytoplasmic domains have 17 and 145 amino acids, respectively. Exons 1 through 5 encode the extracellular region. Exon 6 encodes the transmembrane region. Exons 7-9 encode the intracellular region $(1,2)$.
Extrinsic and intrinsic pathways are the major DR-mediated pathways of apoptosis. Engagement of the DRs with cognate ligands including FasL induces recruitment and activation of the apoptosis-initiating proteases, such as caspase- 8 and caspase-10, and then induces apoptosis through various molecules. By contrast, the binding of some cognate ligands to DR triggers transcriptional events leading to nuclear factor-kappa $\beta$ (NF$\kappa \mathrm{B})$ - or activator protein-1 (AP-1)-dependent pro-inflammatory cytokine expression (Figure 1). DRs, which are members of a subset of the TNF receptor superfamily known as death receptors, possess a cytoplasmic death domain (DD). Fas-mediated apoptosis proceeds through the extrinsic pathway via the binding to their respective receptors of ligands, such as FasL, tumor necrosis factor-alpha (TNF- $\alpha)$, lymphotoxin-alpha (LT- $\alpha)$, TNF-like protein-1A (TL1A), and Apo2L/TNF-related apoptosis-inducing ligand (TRAIL) (Figure 1). FasL is the ligand for the Fas receptor. TNF- $\alpha$ and LT- $\alpha$ are ligands for the TNF superfamily member 1A (TNFR1), TL1A is a ligand for TNF receptor superfamily member 25 (DR3), and TRAIL is a ligand for the TNF receptor superfamily member 10a (DR4/TRAIL-R1) or tumor necrosis factor receptor superfamily member $10 \mathrm{~b}$ (DR5/TRAIL-R2). These receptors are members of a subset of the TNF receptor super family known as DRs. Engagement of DRs of their cognate ligands promotes recruitment and activation of the apoptosisinitiating proteases caspase- 8 and caspase- 10 within membrane

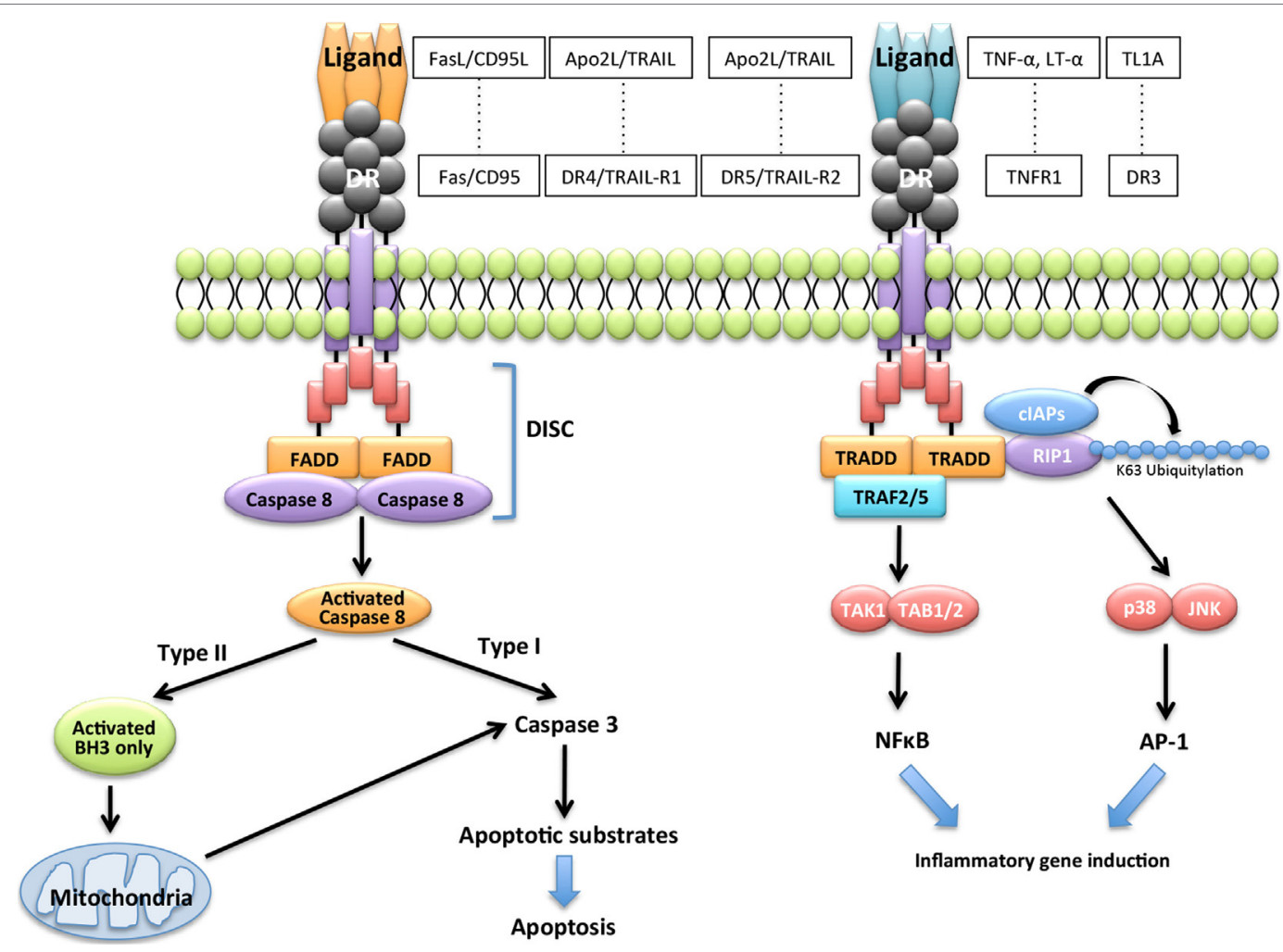

FIGURE 1 | Apoptotic signaling via Fas/FasL. Engagement of the death receptors (DRs) with their cognate ligands, such as FasL/CD95L, tumor necrosis factor-alpha (TNF- $\alpha$ ), lymphotoxin-alpha (LT- $\alpha$ ), TNF-like protein-1A (TL1A), and Apo2L/TNF-related apoptosis-inducing ligand (TRAIL), and their receptors promotes recruitment and activation of the apoptosis-initiating proteases, caspase-8, and caspase-10 and induces transcriptional events leading to nuclear factor-kappa $\beta$ (NF-кB)-dependent pro-inflammatory cytokine expression. 
receptor complexes (25). Apoptosis induced by the engagement of the DRs by their cognate ligands is well understood (26-29) (Figure 1).

Binding of DRs to their cognate ligands recruits one of two pivotal DD-containing adaptor proteins: Fas-associated protein with DD (FADD) or TNF receptor-associated DD (TRADD) (Figure 1). FADD controls cell death by recruiting caspase-8 and caspase-10, TRADD controls non-apoptotic functions by recruiting the DD-containing kinase receptor-interacting protein-1 (30), and the E3 ubiquitin ligases TNF receptor-associating factor 2 (TRAF2) and cellular inhibitor of apoptosis proteins (31). TRADD signaling activates phosphorylation cascades comprising the IKK kinase complex, which phosphorylates the inhibitor of $\mathrm{NF}-\kappa \mathrm{B}$ and the mitogen-activated protein kinases, c-jun N-terminal kinase (JNK), and p38 (Figure 1). The recruiting events initiate a transcriptional program to express genes that induce the synthesis of mediators of inflammation (7-9). DRs can be divided into two categories based on the primary adaptor protein they bind to Fas/CD95/APO-1, DR4/TRAIL-R1 and DR5/TRAIL-R2 bind FADD and mediate mainly proapoptotic functions (Figure 1). By contrast, TNFR1 and DR3 bind TRADD and mediate mainly pro-inflammatory and immune-stimulatory activities (7-9) (Figure 1).

In the Fas-mediated apoptotic pathway, binding of FasL drives Fas clustering and binding of Fas to FADD. FADD recruits caspase- 8 and caspase- 10 to form the death-inducing signaling complex (DISC) (25). DISC is activated by specific post-translational modifications of the DR, such as palmitoylation and O-linked glycosylation $(32,33)$. The DISC mediates autocatalytic processing and activation of caspase- 8 and caspase-10, which propagate the death signal either through proteolysis of effector caspases such as caspases-3, caspase-6, and caspase-7. In type I cells such as thymocytes, processing by effector caspases is sufficient to induce apoptosis (Figure 1). By contrast, apoptosis requires caspase-8-mediated cleavage of $\mathrm{BH} 3$-interacting domain death agonist (Bid), which is a $\mathrm{BH} 3$-only protein that can promote the permeabilization of mitochondrial outer membranes and release of cytochrome $c$ in type II cells such as B cells (Figure 1). Upon release from mitochondria, cytochrome $c$ acts as a cofactor for the assembly of a cytosolic caspase-activating complex called the apoptosome, which propagates the caspase activation cascade (33). Thus, Fas signal has dual pathways of apoptosis and non-apoptosis in various cells.

\section{Fas-MEDIATED T CELL IMMUNE REGULATION}

The negative selection of autoreactive $\mathrm{T}$ cells in thymus is regulated by strong $\mathrm{T}$ cell signals that induce apoptosis through Bcl-2-interacting mediator of cell death (Bim), but not Fas (34). By contrast, apoptosis of activated peripheral T cells is controlled by the intrinsic and extrinsic pathways (34). Antigen stimulation via the T-cell receptor (TCR) contributes to antigen-specific $\mathrm{T}$ cell responses related to cell survival. TCR and Fas signaling are linked, and the AICD of peripheral T cells is controlled by interaction between TCR and Fas signaling (34).
Following TCR ligation, signaling through CD3 complex leads to recruitment of signaling molecules such as lymphocyte-specific protein tyrosine kinase (LCK), phosphorylation of $\zeta$-chainassociated protein kinase 70 (ZAP70), linker for activation of T cells (LAT), phospholipase C $\gamma 1$, VAV, SH2-domain-containing leukocyte protein 76 , and protein kinase $\mathrm{C} \theta$, in coordination with costimulatory molecules such as CD28 and CD4 $(35,36)$ (Figure 2).

Homeostasis of peripheral $\mathrm{T}$ cells is maintained by three mechanisms as follows: unresponsiveness (anergy) of $\mathrm{T}$ cells, suppression by regulatory T cells, and AICD (37). AICD is initiated by repeated stimulation of the TCR through Fas-mediated apoptosis to control the effector T-cell population (38). Further, AICD is induced through the interaction between Fas and FasL, and activated $\mathrm{T}$ cells expressing Fas and FasL are killed either though suicide or by mutual interaction $(39,40)$. During the immune responses, antigen-stimulated effector $\mathrm{T}$ cells are activated to produce various inflammatory cytokines and growth factors. Although the tuning of TCR signaling is controlled by costimulatory molecules such as CD28 and programmed cell death protein-1 (41), the system that declines the activated T cells maintains peripheral tolerance. Overactivated effector T cells are harmful to the immune system, and should be deleted from the periphery. Therefore, AICD induced by Fas-mediated apoptosis plays a potent role in the peripheral immune system (37).

Moreover, impairment of AICD contributes to the onset or development of autoimmunity. Numerous studies of $l \mathrm{pr} /$ lpr or gld/gld mice focused on the relationship between AICD of peripheral $\mathrm{T}$ cells and autoimmunity $(10,11,19,20)$. These studies found that impaired AICD in $l p r / l p r$ or gld/gld mice leads to $\mathrm{T}$ cell dysfunctions and the onset of autoimmune lesions in multiple organs $(10,11,19,20)$. Evidence indicates that autoreactive $\mathrm{T}$ cells are abundant in the periphery of $l p r / l p r$ or gld/gld mice as well as in patients with ALPS $(10,11,19,20)$. By contrast, Fas-independent $\mathrm{T}$ cell apoptosis is induced by the direct interaction between TRAIL-R2 on T cells and TRAIL on Fas-deficient dendritic cells in MRL-lpr/lpr mice (42). Thus, member of the TNFR family, including Fas and TRAIL-R2, likely play a key role in the maintenance of peripheral immune tolerance.

By contrast, Fas mediates apoptotic and non-apoptotic pathways (28). Acting downstream of cellular caspase-8-like inhibitory protein (cFLIP) and TRAF2 in the Fas signaling pathway, T-cell proliferation is induced through NF- $\kappa \mathrm{B}$ activation (43) (Figure 2). The cFLIP N-terminal cleavage products $\mathrm{p} 43$-FLIP and $\mathrm{p} 22-\mathrm{FLIP}$ induce NF- $\mathrm{KB}$ activation by binding to the IKK complex $(44,45)$ (Figure 2). Further, overexpression of cFLIP inhibits Fas-induced apoptosis of activated T cells $(46,47)$. Moreover, Fas signaling regulates peripheral $\mathrm{T}$ cell homeostasis by modulating the equilibrium between proliferation and cell death, for example, in naive and memory $\mathrm{T}$ cell subsets (48). Therefore, homeostasis of peripheral $\mathrm{T}$ cells may be maintained by the dual outocomes of FasL/Fas signaling.

\section{Fas-MEDIATED B CELL IMMUNE REGULATION}

The first report of the expression of FasL on the surface of B cells of wild-type mice but not from $\mathrm{gld} / \mathrm{gld}$ mice demonstrated that 


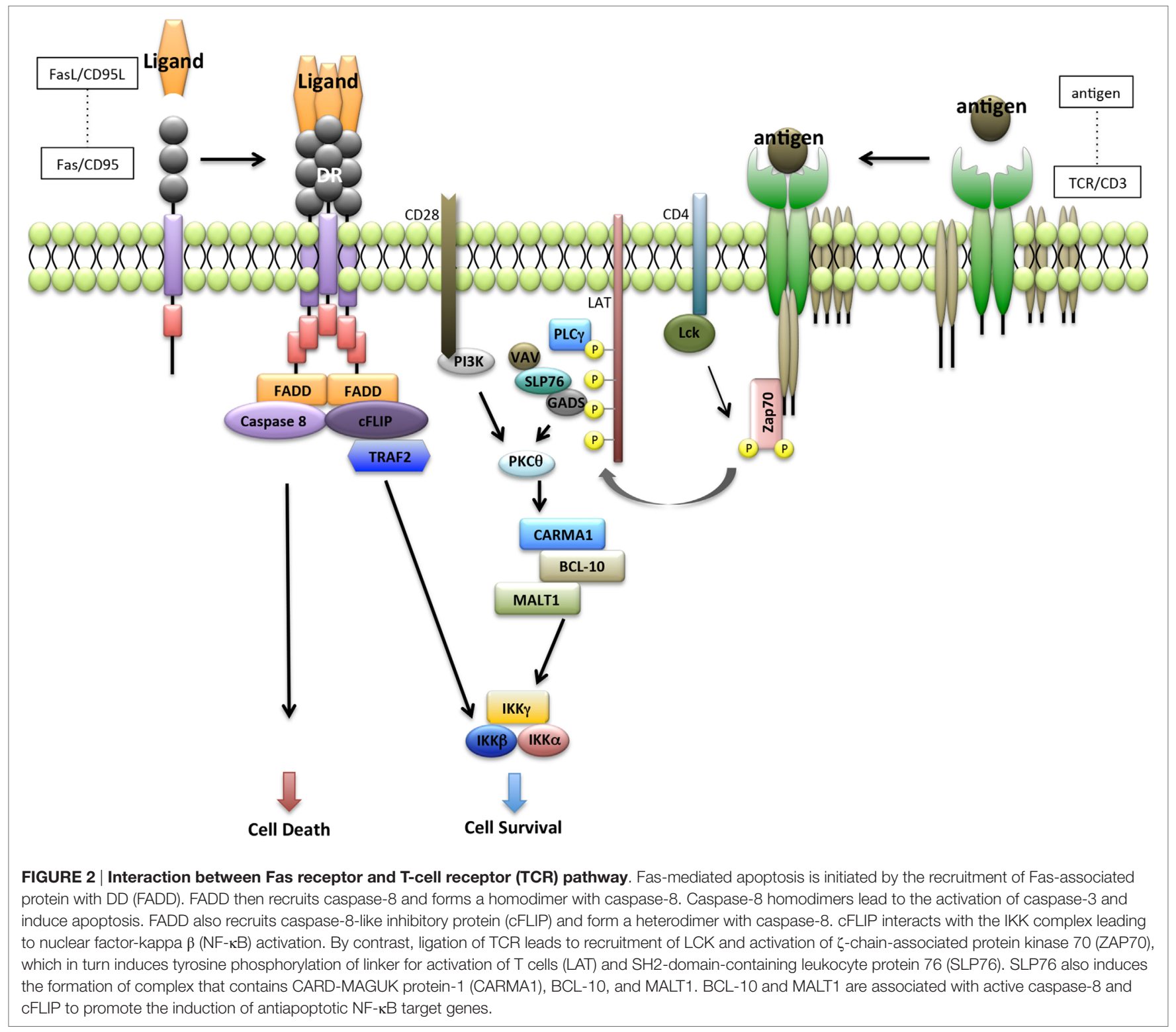

activation of mouse B cells leads to the expression of FasL and killing of Fas-expressing target cells by B cells (49). Further, surface-localized FasL is expressed by human and mouse $\mathrm{B}$ cells, and the abnormal function of FasL ${ }^{+}$killer B cells leads to a novel target for immune modulation in many disease settings (50-52). Moreover, reduction of the number of $\mathrm{FasL}^{+} \mathrm{CD}^{+}$ $\mathrm{B}$ cells is associated with exacerbated severity of arthritis and inhibits T-cell death in a TCR transgenic mouse model with collagen-induced arthritis (53). Deficiency of the FasL/Fas signaling pathway in humans leads to ALPS, which is most often manifested as autoimmune hemolytic anemia, thrombocytopenia, or leukocytopenia, caused by cell-type specific autoantibody production $(54,55)$. Thus, FasL/Fas interactions play a critical role in regulating the production of pathogenic autoantibodies. The killer B cells that produce these autoantibodies may represent a novel modality for inducing T-cell death to treat autoimmunity.
Moreover, the expression of FasL on B cells of individuals infected by human immunodeficiency virus (HIV) (56) and the induction of Epstein-Barr virus of FasL expression by B cells markedly increases the sensitivity of Th cells to Fas-mediated T cell apoptosis (57). Although these data suggest that FasL expression by $B$ cells might play a pathogenic role by inducing $\mathrm{T}$ cell death during viral infections, this hypothesis was not explored.

Findings that $\mathrm{FasL}^{+}$B-chronic lymphocytic leukemia (B-CLL) cells kill a susceptible $\mathrm{CD}^{+} \mathrm{T}$-cell leukemia cell line provided the first direct evidence implicating $\mathrm{B}$ cells in the induction of $\mathrm{T}$ cell apoptosis (52). FasL expression frequently occurs in patients with the aggressive form of B-CLL as well as in other human B-cell leukemias and lymphomas, most notably, multiple myeloma $(58,59)$. These results suggest that killer $B$ cells induced by viral infections and tumor cells play a crucial role in the ability of virus-infected or cancer cells to evade the host's immune system. 
By contrast, Fas is highly expressed in activated and germinal center (GC) B cells. B cell-specific Fas deficiency is associated with the onset of autoimmunity (60), suggesting that Fas prevents the development of self-reactive GC B cells that escape normal regulatory controls and produce high amounts of immunoglobulin and autoantibodies $(60,61)$. Further, MRL-lpr/lpr mice produce circulating autoantibodies, such as rheumatoid factor as well as those against a single- and double-strand DNA and nuclear antigens $(62,63)$, indicating the contribution of FasL/Fas signaling in B cells to cellular processes such as differentiation, proliferation, death, and immunoglobulin production. Thus, Fas signal in B cell plays potent roles in the function and the pathogenesis of immune disorders.

\section{UNIQUE ROLES OF FasL}

FasL is a homotrimeric membrane protein that belongs to the TNF superfamily including CD178, CD95L, and apoptosis antigen-1 (Apo-1) ligand. Human FasL shares 81 and $78 \%$ amino acid sequence identity with its mouse and rat homologs, respectively. FasL comprises a single transmembrane domain, an intracellular domain harboring a proline-rich domain, and an extracellular domain. The latter contains an oligomerization domain required for oligomerization (64).

FasL expression on activated T cells is induced by stimulation via TCR, costimulatory molecules, and cytokine receptors (65). FasL expression is regulated by several transcription factors, including NF- $\kappa \mathrm{B}$, nuclear factor of activated T cells (NF-AT), early growth response gene family transcription factors, c-Myc, AP-1, secretory protein-1, and interferon regulatory factors (66-72).

Matrix metalloproteinase-7 (matrilysin) cleaves FasL to generate $\mathrm{sFasL}$, which is released into the extracellular milieu (73). Abnormal levels of trimeric sFasL $(73,74)$ are detected in sera from patients with large granular lymphocytic leukemia and natural killer (NK) cell lymphoma (3), and other cancers as well as patients with SLE (75). The level of serum sFasL correlated with disease progression $(3,75)$ suggesting that sFasL induces the apoptosis of $\mathrm{Fas}^{+} \mathrm{T}$ cells to evade immune surveillance. Thus, sFasL possesses proapoptotic and antiapoptotic properties depending of cell type and the microenvironment.

Apoptosis induced by FasL requires extensive oligomerization of the Fas receptor to activate the DISC (76), and membrane-bound FasL (mFasL) and sFasL can bind the Fas receptor. However, the naturally cleaved form of sFasL does not form oligomers with the Fas receptor, and therefore sFasL fails to induce apoptosis. Further, sFasL inhibits mFasL-mediated apoptosis through steric hindrance of its binding to the Fas receptor, indicating that $\mathrm{mFas}$ and sFasL have opposite functions that affect cell survival (77-79). For example, sFasL shed by a disintegrin and metalloproteinases or MMPs induces proliferation of fibroblast-like synoviocytes in patients with RA through activation of $\mathrm{v}$-akt murine thymoma viral oncogene homolog (Akt1), extracellular signal-regulated kinase, and JNK (Figure 3) (80). Thus, sFasL has dual functions for cell death and survival.

Loss-of-function mutations in the genes encoding murine and human FasL causes a phenotype similar to that of patients with lymphadenopathy and autoimmune disease because of decreased apoptosis in $\mathrm{Fas}^{+} \mathrm{CD} 4^{-} \mathrm{CD} 8^{-} \mathrm{T}$ lymphocytes and the production of autoantibodies $(81,82)$. In patients with ALPS, germline mutations of FasL gene are associated with defective apoptosis (83). Patients with rare heterozygous FasL gene mutations are classified as type Ib-ALPS (84).

The tissue distribution of FasL, which is predominantly expressed by activated T cells and NK cells, is limited (3). FasL is constitutively expressed by stromal cells of the retina and Sertoli cells of the testis, respectively, which are immunoprivileged tissues. In such tissues, FasL expression leads to the death of invading $\mathrm{Fas}^{+}$cells. The susceptibility of the eyes of gld/gld mice to inflammation (85) and their rejection of corneal allografts prove that FasL plays an important role in sites of immune privilege (24). The ocular immune privilege is believed to be one mechanism by which the visual axis is protected from dangerous immune reactions. Therefore, immunoprivileged site is maintained by the sequestration of any antigens, the lack of lymphatic damage, and the blood-tissue barrier (5). In addition, both Fas and FasL are present on thyroid cells in patients with autoimmune thyroiditis (Hashimoto's thyroiditis) (22). This suggests that Fas/FasL interactions among thyroid cells contribute to the pathogenesis of autoimmune thyroiditis with tissue destruction (22).

FasL is expressed in tumors such as colorectal carcinomas, melanomas, head and neck carcinomas, and myelomas (86). The level of FasL produced by non-immune cells can induce apoptosis in $\mathrm{Fas}^{+} \mathrm{T}$ cells that recognize tissue-specific antigens to evade immune surveillance (86). Moreover, a variety of cell types can express FasL in response to different stimulatory conditions, including macrophages infected with HIV, hepatocytes treated with ethanol, leukemia cells exposed to chemotherapy drugs, as well as cancer cells $(87,88)$. Thus, the unique functions of FasL contribute to various physiological or pathological processes that are not associated with the immune system.

\section{THE Fas/FasL SYSTEM IN AUTOIMMUNITY}

The contribution of Fas-mediated apoptosis to the onset and development of autoimmunity was established by studies of patients with autoimmune diseases and animal models (14, 15, $89,90)$. ALPS is an inherited disorder of the systemic immune system that involves a spontaneous mutation in the Fas or FasL gene $(14,15,21)$. Approximately two-thirds of patients with ALPS bear mutations in the gene encoding Fas (type Ia) $(91,92)$. By contrast, there are few reports of mutations in the genes encoding FasL gene (type Ib) and caspase-10 gene (ALPS type IIa) (92-95), and these mutations are not detected in patients with ALPS type III (96).

The clinical features of patients with ALPS are splenomegaly, lymphadenopathy, and hepatomegaly, which are caused by the accumulation of polyclonal lymphocytes as well as autoimmune lesions in multiple organs. The risk of malignant lymphoma is increased in patients with ALPS (97). Peripheral T cells expressing TCR $\alpha / \beta$, but not $\mathrm{CD} 4$ and $\mathrm{CD} 8\left[\mathrm{CD} 4^{-} \mathrm{CD} 8^{-}\right.$double negative $(\mathrm{DN})]$, proliferate, and their population expands in the patients with ALPS due to an impaired AICD caused by a defect in the 


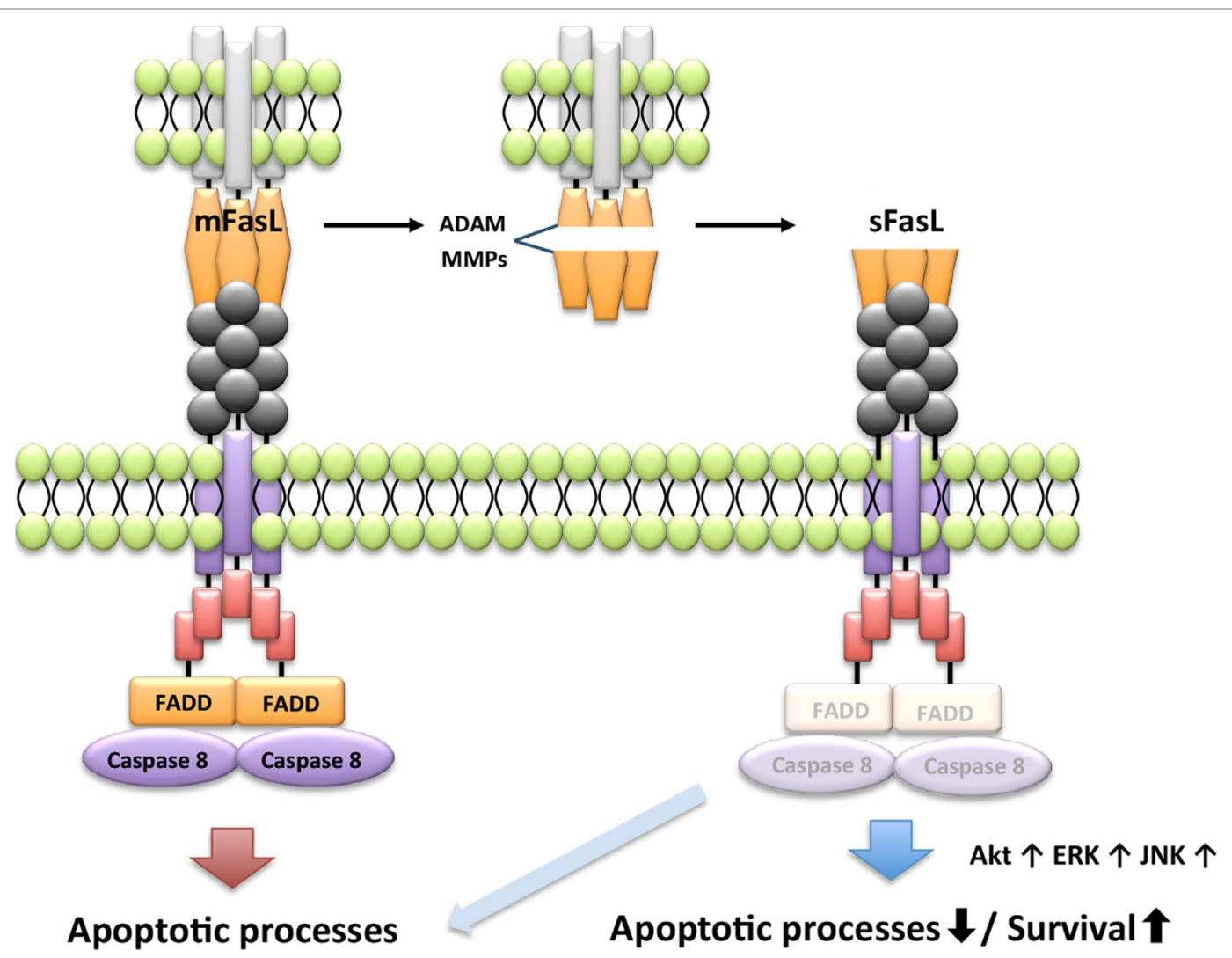

FIGURE 3 | Differential signaling pathway by membrane-bound FasL (mFasL) and soluble FasL (sFasL). mFasL leads to the recruitment of FADD and activates caspase pathways. mFas promotes apoptosis. mFasL is shed by a disintegrin and metalloproteinases (ADAM) or MMPs in the pathological or physiological condition. For instance, sFasL strongly activates extracellular signal-regulated kinase (ERK), $\mathrm{Pl}_{3} \mathrm{~K} / \mathrm{Akt}$, and c-jun N-terminal kinase (JNK) to induce proliferation and inhibit apoptotic activity of the fibroblast-like synoviocytes. Differential signal by the engagement of sFasL is determined by the cell type and the pathologic condition.

Fas/FasL system (98). Further, the abnormal programming of Fas-deficient T cells before the DN T-stage is caused by impaired signaling through the mTOR pathway (99). Moreover, a defect in B-cell selection occurs in patients with ALPS, which is caused by impaired class-switch recombination and somatic hypermutation of the genes encoding immunoglobulins (100). Polymorphisms in the genes encoding Fas and FasL are associated with the susceptibility and severity of autoimmune lesions in patients with RA $(101,102)$ as well as in patients with primary SS (103).

To understand the mechanism of Fas/FasL-mediated apoptosis in vivo, MRL-lpr/lpr mice were used as a model of susceptibility to autoimmune disease before spontaneous mutation of the gene encoding Fas was discovered to affect the onset of autoimmunity in the mice (10). Further, gld/gld mice bearing a spontaneous mutation of the gene encoding FasL are employed as a model for autoimmune disease as well $(19,20)$. Lymphoproliferative lesions in $l p r / l p r$ and gld/gld mice demonstrate that Fas/FasL-mediated apoptosis plays a critical role in controlling the maintenance of peripheral lymphocytes. In particular, Fas/FasL-mediated apoptosis contributes to the AICD of T cells in the periphery (4). Moreover, peripheral T cell apoptosis is induced by FasL expression by macrophages, and apoptotic $\mathrm{T}$ cells are promptly phagocytosed by these macrophages, depending on their level of Fas expression (104). In these experiments, normal T cells of
C57BL/6 (B6) mice were engulfed by macrophages of B6-lpr/lpr mice, which lead to enhanced Fas expression by donor $\mathrm{T}$ cells through IFN- $\gamma / \mathrm{IFN}-\gamma$-receptor signaling (104). These findings revealed that the control of Fas expression by macrophages plays an essential role in maintaining $\mathrm{T}$ cell homeostasis in the peripheral immune system.

By contrast, the expression of Fas or FasL occurs in target organs of patients with autoimmune diseases and in animal models $(105,106)$. High levels of sFasL are present in the synovial fluid of patients with RA (107), which may be associated with Fas-mediated apoptosis of synovial cells, but not the AICD of T cells. Further, sFasL present in the synovial fluid of patients with RA inhibits angiogenesis in RA lesions (108). These observations are consistent with decreased levels of FasL mRNA expression in lacrimal gland tissues and peripheral blood lymphocytes as well as increased levels of Fas and FasL in salivary gland tissues of patients with SS $(109,110)$. These findings implicate Fas-mediated apoptosis in the destruction of target salivary gland tissue.

When we treated SS model mice with an anti-murine FasLspecific monoclonal antibody to protect against Fas-mediated apoptosis of the target salivary gland cells (111), we unexpectedly observed exacerbation of the autoimmune lesions in the salivary and lacrimal glands (111). We found that sFasL is processed by 
TABLE 1 | Relationship between cell type and Fas/FasL expression.

\begin{tabular}{|c|c|c|}
\hline Cell type & $\begin{array}{l}\text { Fas/FasL } \\
\text { expression }\end{array}$ & Remarks \\
\hline T cell & Fas $^{+}$, FasL $^{+}$ & $\begin{array}{l}\text { Activation-induced cell death, } \\
\text { autoimmune lymphoproliferation } \\
\text { syndrome (ALPS), autoimmunity }\end{array}$ \\
\hline B cell & $\mathrm{Fas}^{+}, \mathrm{FasL}^{+}$ & $\begin{array}{l}\text { ALPS, collagen-induced arthritis, virus } \\
\text { infection, germinal center, B-chronic } \\
\text { lymphocytic leukemia }\end{array}$ \\
\hline Natural killer cell & $\mathrm{FasL}^{+}$ & Tumor immunity \\
\hline Macrophage & $\mathrm{Fas}^{+}, \mathrm{FasL}^{+}$ & Peripheral immune tolerance \\
\hline Thyrocyte & $\mathrm{Fas}^{+}, \mathrm{FasL}^{+}$ & Hashimoto's thyroiditis, immune privilege \\
\hline Sertoli cell & $\mathrm{FasL}^{+}$ & Immune privilege \\
\hline Salivary gland cell & $\mathrm{Fas}^{+}$ & Sjögren's syndrome \\
\hline Corneal cell & FasL $^{+}$ & Immune privilege \\
\hline Synovial cell, fluid & $\begin{array}{l}\text { Fas }^{+} \text {, soluble } \\
\text { FasL }\end{array}$ & Rheumatoid arthritis \\
\hline
\end{tabular}

autoantigen-specific $\mathrm{CD}^{+} \mathrm{T}$ cells concomitant with metalloproteinase-9 expression $(65,111)$, indicating that increased sFasL expression inhibits the normal AICD of T cells and leads to the proliferation of autoreactive T cells in this SS model. Moreover, although $\mathrm{mFasL}$, but not $\mathrm{sFasL}$, is essential for cytotoxic activity that guards against lymphadenopathy and autoimmunity (29), it remains unclear whether the relationship between $\mathrm{mFasL}$ and sFasL contributes to the molecular mechanisms of AICD. Thus, the impairment of Fas/FasL system in the peripheral immune

\section{REFERENCES}

1. Nagata S, Golstein P. The Fas death factor. Science (1995) 267:1449-56. doi:10.1126/science.7533326

2. Nagata S. Apoptosis by death factor. Cell (1997) 88:355-65. doi:10.1016/ S0092-8674(00)81874-7

3. Nagata S. Fas ligand-induced apoptosis. Annu Rev Genet (1999) 33:29-55. doi:10.1146/annurev.genet.33.1.29

4. Brunner T, Wasem C, Torgler R, Cima I, Jakob S, Corazza N. Fas (CD95/ Apo-1) ligand regulation in $\mathrm{T}$ cell homeostasis, cell-mediated cytotoxicity and immune pathology. Semin Immunol (2003) 15:167-76. doi:10.1016/ S1044-5323(03)00035-6

5. Green DR, Ferguson TA. The role of Fas ligand in immune privilege. Nat Rev Mol Cell Biol (2001) 2:917-24. doi:10.1038/35103104

6. Siegel RM, Chan FK, Chun HJ, Lenardo MJ. The multifaceted role of Fas signaling in immune cell homeostasis and autoimmunity. Nat Immunol (2000) 1:469-74. doi:10.1038/82712

7. Tibbetts MD, Zheng L, Lenardo MJ. The death effector domain protein family: regulators of cellular homeostasis. Nat Immunol (2003) 4:404-9. doi:10.1038/ni0503-404

8. Samali A, Zhivotovsky B, Jones D, Nagata S, Orrenius S. Apoptosis: cell death defined by caspase activation. Cell Death Differ (1999) 6:495-6. doi:10.1038/ sj.cdd. 4400520

9. Schutze S, Tchikov V, Schneider-Brachert W. Regulation of TNFR1 and CD95 signalling by receptor compartmentalization. Nat Rev Mol Cell Biol (2008) 9:655-62. doi:10.1038/nrm 2430

10. Steinberg AD. MRL-lpr/lpr disease: theories meet Fas. Semin Immunol (1994) 6:55-69. doi:10.1006/smim.1994.1009

11. Singer GG, Carrera AC, Marshak-Rothstein A, Martinez C, Abbas AK. Apoptosis, Fas and systemic autoimmunity: the MRL-lpr/lpr model. Curr Opin Immunol (1994) 6:913-20. doi:10.1016/0952-7915(94)90013-2

12. Roberts AI, Devadas S, Zhang X, Zhang L, Keegan A, Greeneltch K, et al. The role of activation-induced cell death in the differentiation of T-helper-cell subsets. Immunol Res (2003) 28:285-93. doi:10.1385/IR:28:3:285 tolerance considerably contributes to the onset or development of a lot of autoimmune diseases.

\section{CONCLUDING REMARKS}

Some examples regarding the relationship between various cells and Fas/FasL expression are listed in Table 1. Numerous molecules precisely regulate Fas-mediated apoptosis through complicated signaling cascades. Apoptotic and antiapoptotic signaling pathways in $\mathrm{T}$ cells are controlled by the interaction between TCR and Fas signaling pathways and the expression of FasL. Further, the Fas/FasL system plays potent roles in B cell biology. The unique functions of FasL contribute to tumorgenesis, infection, immune disorders as well as to the outcomes of tissue transplantation. Finally, the multiple functions of Fas/ FasL-mediated regulation maintain immune tolerance.

\section{AUTHOR CONTRIBUTIONS}

All authors contributed to the writing of the manuscript. NI conceived and edited the manuscript. YK and MS prepared the figures.

\section{FUNDING}

NI was supported by JSPS KAKENHI (Grant number JP16H02690).

13. Mountz JD, Zhou T, Long RE, Bluethmann H, Koopman WJ, Edwards CK III. T cell influence on superantigen-induced arthritis in MRL-lpr/lpr mice. Arthritis Rheum (1994) 37:113-24. doi:10.1002/art.1780370117

14. Nagata S. Human autoimmune lymphoproliferative syndrome, a defect in the apoptosis-inducing Fas receptor: a lesson from the mouse model. J Hum Genet (1998) 43:2-8. doi:10.1007/s100380050029

15. Rieux-Laucat F, Le Deist F, Fischer A. Autoimmune lymphoproliferative syndromes: genetic defects of apoptosis pathways. Cell Death Differ (2003) 10:124-33. doi:10.1038/sj.cdd.4401190

16. Vargo-Gogola T, Crawford HC, Fingleton B, Matrisian LM. Identification of novel matrix metalloproteinase-7 (matrilysin) cleavage sites in murine and human Fas ligand. Arch Biochem Biophys (2002) 408:155-61. doi:10.1016/ S0003-9861(02)00525-8

17. Garcia AJ, Tom C, Guemes M, Polanco G, Mayorga ME, Wend K, et al. ERalpha signaling regulates MMP3 expression to induce FasL cleavage and osteoclast apoptosis. J Bone Miner Res (2013) 28:283-90. doi:10.1002/jbmr.1747

18. Herrero R, Kajikawa O, Matute-Bello G, Wang Y, Hagimoto N, Mongovin S, et al. The biological activity of FasL in human and mouse lungs is determined by the structure of its stalk region. J Clin Invest (2011) 121:1174-90. doi:10.1172/JCI43004

19. Roths JB, Murphy ED, Eicher EM. A new mutation, gld, that produces lymphoproliferation and autoimmunity in C3H/HeJ mice. J Exp Med (1984) 159:1-20. doi:10.1084/jem.159.1.1

20. Ito MR, Terasaki S, Itoh J, Katoh H, Yonehara S, Nose M. Rheumatic diseases in an MRL strain of mice with a deficit in the functional Fas ligand. Arthritis Rheum (1997) 40:1054-63. doi:10.1002/art.1780400610

21. Yu CC, Mamchak AA, DeFranco AL. Signaling mutations and autoimmunity. Curr Dir Autoimmun (2003) 6:61-88. doi:10.1159/000066856

22. Giordano C, Stassi G, De Maria R, Todaro M, Richiusa P, Papoff G, et al. Potential involvement of Fas and its ligand in the pathogenesis of Hashimoto's thyroiditis. Science (1997) 275:960-3.

23. Hunt JS, Vassmer D, Ferguson TA, Miller L. Fas ligand is positioned in mouse uterus and placenta to prevent trafficking of activated leukocytes between the mother and the conceptus. J Immunol (1997) 158:4122-8. 
24. Stuart PM, Griffith TS, Usui N, Pepose J, Yu X, Ferguson TA. CD95 ligand (FasL)-induced apoptosis is necessary for corneal allograft survival. J Clin Invest (1997) 99:396-402. doi:10.1172/JCI119173

25. Wilson NS, Dixit V, Ashkenazi A. Death receptor signal transducers: nodes of coordination in immune signaling networks. Nat Immunol (2009) 10:348-55. doi:10.1038/ni.1714

26. Dickens LS, Boyd RS, Jukes-Jones R, Hughes MA, Robinson GL, Fairall L, et al. A death effector domain chain DISC model reveals a crucial role for caspase-8 chain assembly in mediating apoptotic cell death. Mol Cell (2012) 47:291-305. doi:10.1016/j.molcel.2012.05.004

27. Falschlehner C, Schaefer U, Walczak H. Following TRAIL's path in the immune system. Immunology (2009) 127:145-54. doi:10.1111/j.1365-2567. 2009.03058.x

28. Lavrik IN, Krammer PH. Regulation of CD95/Fas signaling at the DISC. Cell Death Differ (2012) 19:36-41. doi:10.1038/cdd.2011.155

29. LA OR, Tai L, Lee L, Kruse EA, Grabow S, Fairlie WD, et al. Membranebound Fas ligand only is essential for Fas-induced apoptosis. Nature (2009) 461:659-63. doi:10.1038/nature08402

30. Festjens N, Vanden Berghe T, Cornelis S, Vandenabeele P. RIP1, a kinase on the crossroads of a cell's decision to live or die. Cell Death Differ (2007) 14:400-10. doi:10.1038/sj.cdd.4402085

31. Varfolomeev E, Vucic D. (Un)expected roles of c-IAPs in apoptotic and NFkappaB signaling pathways. Cell Cycle (2008) 7:1511-21. doi:10.4161/ cc.7.11.5959

32. Muppidi JR, Siegel RM. Ligand-independent redistribution of Fas (CD95) into lipid rafts mediates clonotypic T cell death. Nat Immunol (2004) 5:182-9. doi:10.1038/ni1024

33. Wagner KW, Punnoose EA, Januario T, Lawrence DA, Pitti RM, Lancaster K, et al. Death-receptor O-glycosylation controls tumor-cell sensitivity to the proapoptotic ligand Apo2L/TRAIL. Nat Med (2007) 13:1070-7. doi:10.1038/ nm1627

34. Bouillet P, O'Reilly LA. CD95, BIM and T cell homeostasis. Nat Rev Immunol (2009) 9:514-9. doi:10.1038/nri2570

35. Chakraborty AK, Weiss A. Insights into the initiation of TCR signaling. Nat Immunol (2014) 15:798-807. doi:10.1038/ni.2940

36. Abraham RT, Weiss A. Jurkat T cells and development of the T-cell receptor signalling paradigm. Nat Rev Immunol (2004) 4:301-8. doi:10.1038/nri1330

37. Mueller DL. Mechanisms maintaining peripheral tolerance. Nat Immunol (2010) 11:21-7. doi:10.1038/ni.1817

38. Green DR, Droin N, Pinkoski M. Activation-induced cell death in T cells. Immunol Rev (2003) 193:70-81. doi:10.1034/j.1600-065X.2003.00051.x

39. Alderson MR, Tough TW, Davis-Smith T, Braddy S, Falk B, Schooley KA, et al. Fas ligand mediates activation-induced cell death in human T lymphocytes. J Exp Med (1995) 181:71-7. doi:10.1084/jem.181.1.71

40. Varadhachary AS, Perdow SN, Hu C, Ramanarayanan M, Salgame P. Differential ability of $\mathrm{T}$ cell subsets to undergo activation-induced cell death. Proc Natl Acad Sci U S A (1997) 94:5778-83. doi:10.1073/pnas.94.11.5778

41. Najafian N, Khoury SJ. T cell costimulatory pathways: blockade for autoimmunity. Expert Opin Biol Ther (2003) 3:227-36. doi:10.1517/14712598.3.2.227

42. Izawa T, Kondo T, Kurosawa M, Oura R, Matsumoto K, Tanaka E, et al. Fas-independent T-cell apoptosis by dendritic cells controls autoimmune arthritis in MRL/lpr mice. PLoS One (2012) 7:e48798. doi:10.1371/journal. pone. 0048798

43. Kataoka T, Tschopp J. N-terminal fragment of c-FLIP(L) processed by caspase 8 specifically interacts with TRAF2 and induces activation of the NF-kappaB signaling pathway. Mol Cell Biol (2004) 24:2627-36. doi:10.1128/ MCB.24.7.2627-2636.2004

44. Golks A, Brenner D, Krammer PH, Lavrik IN. The c-FLIP-NH2 terminus (p22-FLIP) induces NF-kappaB activation. J Exp Med (2006) 203:1295-305. doi:10.1084/jem.20051556

45. Krammer PH, Arnold R, Lavrik IN. Life and death in peripheral T cells. Nat Rev Immunol (2007) 7:532-42. doi:10.1038/nri2115

46. Van Parijs L, Refaeli Y, Abbas AK, Baltimore D. Autoimmunity as a consequence of retrovirus-mediated expression of c-FLIP in lymphocytes. Immunity (1999) 11:763-70. doi:10.1016/S1074-7613(00)80150-8

47. Kirchhoff S, Muller WW, Krueger A, Schmitz I, Krammer PH. TCR-mediated up-regulation of c-FLIPshort correlates with resistance toward CD95mediated apoptosis by blocking death-inducing signaling complex activity. J Immunol (2000) 165:6293-300. doi:10.4049/jimmunol.165.11.6293
48. Jaleco S, Swainson L, Dardalhon V, Burjanadze M, Kinet S, Taylor N. Homeostasis of naive and memory CD4+ T cells: IL-2 and IL-7 differentially regulate the balance between proliferation and Fas-mediated apoptosis. J Immunol (2003) 171:61-8. doi:10.4049/jimmunol.171.1.61

49. Hahne M, Renno T, Schroeter M, Irmler M, French L, Bornard T, et al. Activated B cells express functional Fas ligand. Eur J Immunol (1996) 26:721-4. doi:10.1002/eji.1830260332

50. Mullauer L, Mosberger I, Chott A. Fas ligand expression in nodal non-Hodgkin's lymphoma. Mod Pathol (1998) 11:369-75.

51. Mariani SM, Krammer PH. Differential regulation of TRAIL and CD95 ligand in transformed cells of the $\mathrm{T}$ and B lymphocyte lineage. Eur J Immunol (1998) 28:973-82. doi:10.1002/(SICI)1521-4141(199803)28:03<973::AIDIMMU973>3.0.CO;2-T

52. Tinhofer I, Marschitz I, Kos M, Henn T, Egle A, Villunger A, et al. Differential sensitivity of CD4+ and CD8+ T lymphocytes to the killing efficacy of Fas (Apo-1/CD95) ligand+ tumor cells in B chronic lymphocytic leukemia. Blood (1998) 91:4273-81.

53. Lundy SK, Fox DA. Reduced Fas ligand-expressing splenic CD5+ B lymphocytes in severe collagen-induced arthritis. Arthritis Res Ther (2009) 11:R128. doi:10.1186/ar2795

54. Turbyville JC, Rao VK. The autoimmune lymphoproliferative syndrome: a rare disorder providing clues about normal tolerance. Autoimmun Rev (2010) 9:488-93. doi:10.1016/j.autrev.2010.02.007

55. Price S, Shaw PA, Seitz A, Joshi G, Davis J, Niemela JE, et al. Natural history of autoimmune lymphoproliferative syndrome associated with FAS gene mutations. Blood (2014) 123:1989-99. doi:10.1182/blood-2013-10-535393

56. Samuelsson A, Sonnerborg A, Heuts N, Coster J, Chiodi F. Progressive B cell apoptosis and expression of Fas ligand during human immunodeficiency virus type 1 infection. AIDS Res Hum Retroviruses (1997) 13:1031-8. doi:10.1089/aid.1997.13.1031

57. Tanner JE, Alfieri C. Epstein-Barr virus induces Fas (CD95) in T cells and Fas ligand in B cells leading to T-cell apoptosis. Blood (1999) 94:3439-47.

58. Sampalo A, Navas G, Medina F, Segundo C, Camara C, Brieva JA. Chronic lymphocytic leukemia B cells inhibit spontaneous Ig production by autologous bone marrow cells: role of CD95-CD95L interaction. Blood (2000) 96:3168-74.

59. Hekimgil M, Cagirgan S, Pehlivan M, Doganavsargil B, Tombuloglu M, Soydan S. Immunohistochemical detection of CD 95 (Fas) \& Fas ligand (Fas-L) in plasma cells of multiple myeloma and its correlation with survival. Leuk Lymphoma (2006) 47:271-80. doi:10.1080/10428190500286218

60. Hao Z, Duncan GS, Seagal J, Su YW, Hong C, Haight J, et al. Fas receptor expression in germinal-center $\mathrm{B}$ cells is essential for $\mathrm{T}$ and $\mathrm{B}$ lymphocyte homeostasis. Immunity (2008) 29(4):615-27. doi:10.1016/j.immuni.2008.07.016

61. Butt D, Chan TD, Bourne K, Hermes JR, Nguyen A, Statham A, et al. FAS inactivation releases unconventional germinal center B cells that escape antigen control and drive IgE and autoantibody production. Immunity (2015) 42:890-902. doi:10.1016/j.immuni.2015.04.010

62. Madaio MP, Yanase K, Foster MH, Smith RM, Emmons TK, Fabbi M, et al. Nuclear localization of autoantibodies. Novel insights into protein translocation and cellular function. Ann N Y Acad Sci (1997) 815:263-6. doi:10.1111/ j.1749-6632.1997.tb52068.x

63. Erikson J, Mandik L, Bui A, Eaton A, Noorchashm H, Nguyen KA, et al. Self-reactive B cells in nonautoimmune and autoimmune mice. Immunol Res (1998) 17:49-61. doi:10.1007/BF02786430

64. Orlinick JR, Elkon KB, Chao MV. Separate domains of the human fas ligand dictate self-association and receptor binding. J Biol Chem (1997) 272:32221-9. doi:10.1074/jbc.272.51.32221

65. Arakaki R, Yamada A, Kudo Y, Hayashi Y, Ishimaru N. Mechanism of activation-induced cell death of T cells and regulation of FasL expression. Crit Rev Immunol (2014) 34:301-14. doi:10.1615/CritRevImmunol.2014009988

66. Karin M, Lin A. NF-kappaB at the crossroads of life and death. Nat Immunol (2002) 3:221-7. doi:10.1038/ni0302-221

67. Kasibhatla S, Genestier L, Green DR. Regulation of fas-ligand expression during activation-induced cell death in T lymphocytes via nuclear factor kappaB. J Biol Chem (1999) 274:987-92. doi:10.1074/jbc.274.2.987

68. Hodge MR, Ranger AM, Charles de la Brousse F, Hoey T, Grusby MJ, Glimcher LH. Hyperproliferation and dysregulation of IL-4 expression in NF-ATp-deficient mice. Immunity (1996) 4:397-405. doi:10.1016/ S1074-7613(00)80253-8 
69. Baumann S, Hess J, Eichhorst ST, Krueger A, Angel P, Krammer PH, et al. An unexpected role for FosB in activation-induced cell death of T cells. Oncogene (2003) 22:1333-9. doi:10.1038/sj.onc.1206126

70. Mages HW, Baag R, Steiner B, Kroczek RA. Utilization of an NF-ATp binding promoter element for EGR3 expression in T cells but not fibroblasts provides a molecular model for the lymphoid cell-specific effect of cyclosporin A. $\mathrm{Mol}$ Cell Biol (1998) 18:7157-65. doi:10.1128/MCB.18.12.7157

71. Genestier L, Kasibhatla S, Brunner T, Green DR. Transforming growth factor betal inhibits Fas ligand expression and subsequent activation-induced cell death in T cells via downregulation of c-Myc. J Exp Med (1999) 189:231-9. doi:10.1084/jem.189.2.231

72. Zhu Y, Swanson BJ, Wang M, Hildeman DA, Schaefer BC, Liu X, et al. Constitutive association of the proapoptotic protein Bim with Bcl-2-related proteins on mitochondria in T cells. ProcNatlAcad Sci USA (2004) 101:7681-6. doi:10.1073/pnas.0402293101

73. Tanaka M, Suda T, Takahashi T, Nagata S. Expression of the functional soluble form of human fas ligand in activated lymphocytes. EMBO J (1995) 14:1129-35.

74. Tanaka M, Suda T, Haze K, Nakamura N, Sato K, Kimura F, et al. Fas ligand in human serum. Nat Med (1996) 2:317-22. doi:10.1038/nm0396-317

75. O'Connell J, Bennett MW, O'Sullivan GC, Collins JK, Shanahan F. The Fas counterattack: cancer as a site of immune privilege. Immunol Today (1999) 20:46-52. doi:10.1016/S0167-5699(98)01382-6

76. Varadhachary AS, Edidin M, Hanlon AM, Peter ME, Krammer PH, Salgame P. Phosphatidylinositol 3'-kinase blocks CD95 aggregation and caspase- 8 cleavage at the death-inducing signaling complex by modulating lateral diffusion of CD95. J Immunol (2001) 166:6564-9. doi:10.4049/ jimmunol.166.11.6564

77. Huang DC, Hahne M, Schroeter M, Frei K, Fontana A, Villunger A, et al. Activation of Fas by FasL induces apoptosis by a mechanism that cannot be blocked by Bcl-2 or Bcl-x(L). Proc Natl Acad Sci U S A (1999) 96:14871-6. doi:10.1073/pnas.96.26.14871

78. Suda T, Hashimoto H, Tanaka M, Ochi T, Nagata S. Membrane Fas ligand kills human peripheral blood T lymphocytes, and soluble Fas ligand blocks the killing. J Exp Med (1997) 186:2045-50. doi:10.1084/jem.186.12.2045

79. Hohlbaum AM, Moe S, Marshak-Rothstein A. Opposing effects of transmembrane and soluble Fas ligand expression on inflammation and tumor cell survival. J Exp Med (2000) 191:1209-20. doi:10.1084/jem.191.7.1209

80. Calmon-Hamaty F, Audo R, Combe B, Morel J, Hahne M. Targeting the Fas/ FasL system in rheumatoid arthritis therapy: promising or risky? Cytokine (2015) 75:228-33. doi:10.1016/j.cyto.2014.10.004

81. Fisher GH, Rosenberg FJ, Straus SE, Dale JK, Middleton LA, Lin AY, et al. Dominant interfering Fas gene mutations impair apoptosis in a human autoimmune lymphoproliferative syndrome. Cell (1995) 81:935-46. doi:10.1016/0092-8674(95)90013-6

82. Wu J, Wilson J, He J, Xiang L, Schur PH, Mountz JD. Fas ligand mutation in a patient with systemic lupus erythematosus and lymphoproliferative disease. J Clin Invest (1996) 98:1107-13. doi:10.1172/JCI118892

83. Del-Rey M, Ruiz-Contreras J, Bosque A, Calleja S, Gomez-Rial J, Roldan E, et al. A homozygous Fas ligand gene mutation in a patient causes a new type of autoimmune lymphoproliferative syndrome. Blood (2006) 108:1306-12. doi:10.1182/blood-2006-04-015776

84. Rieux-Laucat F, Fischer A, Deist FL. Cell-death signaling and human disease. Curr Opin Immunol (2003) 15:325-31. doi:10.1016/ S0952-7915(03)00042-6

85. Griffith TS, Brunner T, Fletcher SM, Green DR, Ferguson TA. Fas ligand-induced apoptosis as a mechanism of immune privilege. Science (1995) 270:1189-92. doi:10.1126/science.270.5239.1189

86. Hahne M, Rimoldi D, Schroter M, Romero P, Schreier M, French LE, et al. Melanoma cell expression of Fas(Apo-1/CD95) ligand: implications for tumor immune escape. Science (1996) 274:1363-6. doi:10.1126/science.274. 5291.1363

87. Westendorp MO, Frank R, Ochsenbauer C, Stricker K, Dhein J, Walczak H, et al. Sensitization of T cells to CD95-mediated apoptosis by HIV-1 Tat and gp120. Nature (1995) 375:497-500. doi:10.1038/375497a0

88. Badley AD, Dockrell D, Simpson M, Schut R, Lynch DH, Leibson P, et al. Macrophage-dependent apoptosis of CD4+ T lymphocytes from HIVinfected individuals is mediated by FasL and tumor necrosis factor. J Exp Med (1997) 185:55-64. doi:10.1084/jem.185.1.55
89. Mountz JD, Wu J, Cheng J, Zhou T. Autoimmune disease. A problem of defective apoptosis. Arthritis Rheum (1994) 37:1415-20. doi:10.1002/ art.1780371002

90. Suda T, Nagata S. Why do defects in the Fas-Fas ligand system cause autoimmunity? J Allergy Clin Immunol (1997) 100:S97-101. doi:10.1016/S00916749(97)70013-7

91. Oliveira JB, Fleisher T. Autoimmune lymphoproliferative syndrome. Curr Opin Allergy Clin Immunol (2004) 4:497-503. doi:10.1097/00130832200412000-00005

92. Shah S, Wu E, Rao VK, Tarrant TK. Autoimmune lymphoproliferative syndrome: an update and review of the literature. Curr Allergy Asthma Rep (2014) 14:462. doi:10.1007/s11882-014-0462-4

93. Jackson CE, Puck JM. Autoimmune lymphoproliferative syndrome, a disorder of apoptosis. Curr Opin Pediatr (1999) 11:521-7. doi:10.1097/00008480-199912000-00009

94. Sezgin M, Barlas IO, Yildir S, Turkoz G, Ankarali HC, Sahin G, et al. Apoptosis-related Fas and FasL gene polymorphisms' associations with knee osteoarthritis. Rheumatol Int (2013) 33:2039-43. doi:10.1007/ s00296-013-2688-1

95. Tadaki H, Saitsu H, Kanegane H, Miyake N, Imagawa T, Kikuchi M, et al. Exonic deletion of CASP10 in a patient presenting with systemic juvenile idiopathic arthritis, but not with autoimmune lymphoproliferative syndrome type IIa. Int J Immunogenet (2011) 38:287-93. doi:10.1111/j.1744313X.2011.01005.x

96. van der Werff ten Bosch J, Otten J, Thielemans K. Autoimmune lymphoproliferative syndrome type III, an indefinite disorder. Leuk Lymphoma (2001) 41:501-11. doi:10.3109/10428190109060341

97. Li P, Huang P, Yang Y, Hao M, Peng H, Li F. Updated Understanding of autoimmune lymphoproliferative syndrome (ALPS). Clin Rev Allergy Immunol (2016) 50:55-63. doi:10.1007/s12016-015-8466-y

98. Bristeau-Leprince A, Mateo V,Lim A, Magerus-Chatinet A, SolaryE, Fischer A, et al. Human TCR alpha/beta+ CD4-CD8- double-negative T cells in patients with autoimmune lymphoproliferative syndrome express restricted Vbeta TCR diversity and are clonally related to CD8+ T cells. J Immunol (2008) 181:440-8. doi:10.4049/jimmunol.181.1.440

99. Volkl S, Rensing-Ehl A, Allgauer A, Schreiner E, Lorenz MR, Rohr J, et al. Hyperactive mTOR pathway promotes lymphoproliferation and abnormal differentiation in autoimmune lymphoproliferative syndrome. Blood (2016) 128(2):227-38. doi:10.1182/blood-2015-11-685024

100. Janda A, Schwarz K, van der Burg M, Vach W, Ijspeert H, Lorenz MR, et al. Disturbed B-lymphocyte selection in autoimmune lymphoproliferative syndrome. Blood (2016) 127:2193-202. doi:10.1182/blood-201504-642488

101. Yildir S, Sezgin M, Barlas IO, Turkoz G, Ankarali HC, Sahin G, et al. Relation of the Fas and FasL gene polymorphisms with susceptibility to and severity of rheumatoid arthritis. Rheumatol Int (2013) 33:2637-45. doi:10.1007/ s00296-013-2793-1

102. Mohammadzadeh A, Pourfathollah AA, Tahoori MT, Daneshmandi S, Langroudi L, Akhlaghi M. Evaluation of apoptosis-related gene Fas (CD95) and FasL (CD178) polymorphisms in Iranian rheumatoid arthritis patients. Rheumatol Int (2012) 32:2833-6. doi:10.1007/s00296-011-2065-x

103. Bolstad AI, Wargelius A, Nakken B, Haga HJ, Jonsson R. Fas and Fas ligand gene polymorphisms in primary Sjogren's syndrome. J Rheumatol (2000) 27:2397-405.

104. Oura R, Arakaki R, Yamada A, Kudo Y, Tanaka E, Hayashi Y, et al. Induction of rapid $\mathrm{T}$ cell death and phagocytic activity by Fas-deficient lpr macrophages. J Immunol (2013) 190:578-85. doi:10.4049/jimmunol.1103794

105. Kong L, Ogawa N, Nakabayashi T, Liu GT, D’Souza E, McGuff HS, et al. Fas and Fas ligand expression in the salivary glands of patients with primary Sjogren's syndrome. Arthritis Rheum (1997) 40:87-97. doi:10.1002/ art.1780400113

106. Ishimaru N, Yoneda T, Saegusa K, Yanagi K, Haneji N, Moriyama K, et al. Severe destructive autoimmune lesions with aging in murine Sjogren's syndrome through Fas-mediated apoptosis. Am J Pathol (2000) 156:1557-64. doi:10.1016/S0002-9440(10)65027-4

107. Matsuno H, Yudoh K, Watanabe Y, Nakazawa F, Aono H, Kimura T. Stromelysin-1 (MMP-3) in synovial fluid of patients with rheumatoid arthritis has potential to cleave membrane bound Fas ligand. J Rheumatol (2001) 28:22-8. 
108. Kim WU, Kwok SK, Hong KH, Yoo SA, Kong JS, Choe J, et al. Soluble Fas ligand inhibits angiogenesis in rheumatoid arthritis. Arthritis Res Ther (2007) 9:R42. doi:10.1186/ar2181

109. Tsuzaka K, Matsumoto Y, Sasaki Y, Abe T, Tsubota K, Takeuchi T. Downregulation of Fas-ligand mRNA in Sjogren's syndrome patients with enlarged exocrine glands. Autoimmunity (2007) 40:497-502. doi:10.1080/ 08916930701580320

110. Bolstad AI, Eiken HG, Rosenlund B, Alarcon-Riquelme ME, Jonsson R. Increased salivary gland tissue expression of Fas, Fas ligand, cytotoxic T lymphocyte-associated antigen 4, and programmed cell death 1 in primary Sjogren's syndrome. Arthritis Rheum (2003) 48:174-85. doi:10.1002/art.10734

111. Ishimaru N, Yanagi K, Ogawa K, Suda T, Saito I, Hayashi Y. Possible role of organ-specific autoantigen for Fas ligand-mediated activation-induced cell death in murine Sjogren's syndrome. J Immunol (2001) 167:6031-7. doi:10.4049/jimmunol.167.10.6031

Conflict of Interest Statement: The authors declare that the research was conducted in the absence of any commercial or financial relationships that could be construed as a potential conflict of interest.

Copyright (c) 2017 Yamada, Arakaki, Saito, Kudo and Ishimaru. This is an openaccess article distributed under the terms of the Creative Commons Attribution License (CC BY). The use, distribution or reproduction in other forums is permitted, provided the original author(s) or licensor are credited and that the original publication in this journal is cited, in accordance with accepted academic practice. No use, distribution or reproduction is permitted which does not comply with these terms. 